\title{
Editorial
}

\section{Addressing Reviewer Comments as an Integrative Negotiation}

\author{
Leigh Anne Liu
}

Georgia State University, USA

I frame the process of 'revise and resubmit' as an integrative negotiation where the authors collaborate with the reviewers and editors to reach a mutually agreeable outcome - a publishable manuscript. Like an integrative negotiation, the revision process takes time, concerted effort, collaborative engagement, and the end result adds value for the common good. Strategies for integrative negotiation, such as focusing on interests and core principles and coalition building may facilitate the survival and development of a manuscript.

I propose that we can treat an editorial decision of 'revise and resubmit' as an invitation to start a negotiation. Negotiation is a communicative exchange and joint decision-making process (Lewicki, Barry, \& Saunders, 2010; Putnam \& Jones, 1982). This essay attempts to bridge the interactions among authors, editors, and reviewers with the interactions among negotiators who seek mutually satisfying outcomes. I discuss how strategies of integrative negotiation can empower the authors to engage editors and reviewers to collectively improve the quality of the manuscript.

Novice negotiators often think of negotiation as a 'fixed pie' or a distributive interaction, where one party wins and the other loses (e.g., Thompson, 2012). In distributive negotiations the underlying dynamic is often built on leveraging power instead of exploring each party's rights or interests (Ury, Brett, \& Goldberg, 1988). The authors could treat the invitation to revise and resubmit as a distributive negotiation in one of two ways: by giving the editors and reviewers absolute power and complying with their demands submissively, or by contesting editor and reviewer comments to defend the original paper. Treating the revision as a distributive situation could lead to a manuscript driven more by reviewers and editors, or may sacrifice opportunities to improve the manuscript with fresh ideas from the 
reviewers. Some reviewer comments may be unreasonable or unrealistic to implement, but considering them with an open mind can still bring learning and improvement for the authors. On the other hand, although some reviewers or editors may expect full compliance with their suggestions, authors could persuade them otherwise when less than full compliance would result in a more focused manuscript with a more significant contribution. Thus, it is possible to view the revision process through another lens - as a negotiation of a different sort.

The most fruitful type of negotiation, integrative negotiation, encompasses a process where parties collaborate to reach a mutually satisfying agreement (Fisher, Ury, \& Patton, 2011; Lewicki et al., 2010). In most cases, the editorial review process involves a combination of complying with and persuading the reviewers and editors. I propose that we can apply strategies for integrative negotiation in the revision process to clarify and satisfy the needs of all parties - authors, reviewers, and editors - yielding a final version of the manuscript that represents an outcome better than any individual party's single contribution. Although addressing reviewer comments is not a face-to-face negotiation where negotiators can freely ask and respond to questions in real time, framing the revision as a virtual negotiation with reviewers and the editor can help empower the authors in this joint decision-making process. Below I elucidate, from an author's perspective, how we can apply four integrative negotiation strategies in the journal article revision process.

\section{FOGUS ON INTEREST, NOT POSITIONS}

In negotiation, a position refers to what one wants, while an interest refers to the underlying reason for wanting it (Fisher et al., 2011). In the revision process, some of the reviewers' requests for changing theoretical arguments or for additional data collection and analysis can be construed as positions. Authors can seek to understand the deeper level interests behind those demands, which could reflect a desire for a more coherent theoretical framework or greater certainty about empirical results. As is often the case in actual negotiations, the positions may come off as hostile or unreasonable, whereas the interests, once we understand them, are likely to seem more acceptable and reasonable. Fisher et al. (2011) describe the classic case of the negotiation between the Israelis and the Egyptians over the Sinai Peninsula in 1978. Both parties' stated positions were to occupy the Peninsula, but after several rounds of deliberations, the negotiators and facilitators discovered that the underlying interest of the Egyptians was a desire for sovereignty while the interest of the Israelis was a desire for security. The final outcome of the negotiation was that the Egyptians gained full sovereignty but agreed to demilitarize part of the Peninsula so as to satisfy both parties' interests.

Understanding the underlying interests of each party sets the stage for integrative bargaining and mutually beneficial outcomes. Likewise, it is important for the 
authors to take time to truly understand the real concerns of the reviewers in order to address them effectively, or the rushed revision may result in only 'cosmetic changes' that can be disastrous (Rindova, 2008). It may be hard to get to those interests when first looking at the reviews; we all get defensive about criticism on first glance. Therefore it is generally good advice to set aside the reviews after first reading them and come back to them with a less defensive posture. Discovering reviewers' interests requires a thorough understanding of the written comments, prioritized by the editor, and sometimes with additional clarification by the editor. A clear understanding of reviewer concerns (interests) is the critical foundation of an effective response to those concerns.

\section{INTEGRATE DIVERGENT IDEAS TO IMPROVE 'GRAFTSMANSHIP’}

Since the peer review process is highly subjective and empirical works in organization science only explain a small fraction of the variance (e.g., Daft \& Lewin, 2008), the reviewers and editors may provide competing or alternative interpretations that explain the same empirical results, as well as what theories might explain the large unexplained variance. Treating the revise-and-resubmit process as an integrative negotiation, open-minded authors would embrace the opportunity to engage the editors and reviewers to learn about the alternative theories and integrate these divergent ideas into the revision. As a result, such an integrative process would improve the rigour, relevance, and 'craftsmanship' of the manuscript.

Practically, discussing the journal article review process, Murnighan (1996) uses the metaphor of a recipe entered in a cooking contest. The reviewers' comments are suggestions from the judges that will make the dish taste better and provide a better eating experience. Murnighan (1996) explains that just as some suggestions may not make the dish taste better, the authors do not have to follow all of the reviewers' suggestions. Further, as with a cooking contest, there is always the chance to enter and win another contest. Not all reviewer comments are of equal value or importance. Better reviews help the authors clarify and crystalize the main contributions, but sometimes a strong argument by a reviewer may overshadow the main thrust of a paper and unintentionally divert the authors away from their core contribution. The editor often helps the authors to prioritize important issues to address across different reviewers with a roadmap (Rindova, 2008). However, it is the authors' responsibility to keep an eye on the big picture of a paper's core contribution, use the editor and reviewers' comments to enrich the rigour and relevance, and strive to meet the highest standards of the journal.

\section{OVERGOME EMOTIONAL REACTIONS}

During negotiations, when emotions become heated and tense, experts often advise negotiators to diffuse emotions by (i) taking a break and (ii) focusing on 
specific and tangible small steps. Similar strategies can help authors manage emotions experienced during the revision process. When reviewer comments are first received, authors may perceive them as overwhelmingly negative, eliciting anger, fear, and frustration. Criticisms based on assertions without elaboration or logic behind them such as 'inadequate theoretical contributions', 'why did you study such variables?' and 'your research is not important' may exacerbate such emotional reactions. Seasoned authors often advise newcomers to let the comments sit for a few days, and let the initial emotional reactions pass before going back to work on a strategy to address them. When it is time to work on the revision, Ashford (1996) advises breaking down the reviewer comments by points, making a response template, and then answering them one by one. With this 'divide and conquer' strategy, the authors can address the easy questions first, build momentum for the more difficult issues, and cultivate a more upbeat spirit; in this way, the revision process becomes more manageable. Being able to respond to vague comments such as 'inadequate theoretical contributions' or 'why the study is important' with concrete reasons may also motivate the authors to clarify their reasoning and as a result cultivate self-efficacy and confidence in the research.

This strategy goes hand in hand with another principle in integrative negotiation: be tough on the issues while being soft on the people involved (Fisher et al., 2011). By breaking down reviewer comments into smaller manageable points, authors can focus on the issues specific to the content of the manuscript, rather than ruminating (and, at times, fuming) on the imaginary attributes of reviewers. In this way, the authors can actively divert their anxiety and frustration to focus on concrete steps to improve the manuscript.

\section{NAVIGATE POWER DISTANGE WITH COALITIONS}

If a publishable paper is comparable to a finished sculpture, the initial submission may present only a rough shape with some details. The collective ideas from the authors, the editor, and the reviewers together shape and polish a submission before the paper reaches its final configuration. The authors are ultimately the sculptors, even though the editors and reviewers stand higher in the power structure. As mentioned earlier, sometimes critiques from the editor and reviewers may not be consistent or coherent. In such situations, it is up to the authors to decide which ones to follow. These decisions become more difficult in the often asymmetrical power relationships with editors and reviewers, who may hold more senior positions in the academic community.

In multiparty negotiations, coalitions often emerge based on mutual interests, such as information or resources (Murnighan, 1986), and members of a majority coalition have better opportunities for satisfactory outcomes. In the review process, although the action editor and the reviewers are natural allies, the authors can still build a coalition with the editor or more supportive reviewers whose views on the 
manuscript are closer to those of the authors. Tsui and Hollenbeck (2009) point out that journal reviewers and editors serve a significant advisory function. This particularly resonates with the action editor when the authors seek additional advice on the revision, such as how to best reconcile reviewers' competing recommendations. Negotiation research shows that the party with less power can improve outcomes by asking diagnostic questions and showing a willingness to cooperate (e.g., De Dreu \& Van Kleef, 2004). On a given revise-and-resubmit issue, the authors' choice to comply with one reviewer's comments may dissatisfy another reviewer who had a competing or contradictory suggestion. This presents an opportunity to treat the friendlier reviewer as an ally in order to diffuse the concerns of the dissatisfied reviewer. Also, when authors use novel theories or techniques with which some reviewers may not be familiar but be stubbornly against, external experts who are not involved in the review process can be enlisted as allies to provide additional information and attest to the validity and reliability of the new idea. With consent from the external experts, their opinions can be included in correspondence with the editor in private, or together with the reviewers, for additional support of the author's ideas. With persuasive evidence, supportive editors and open-minded reviewers (Hempel, 2014; Tsang, 2014) may eventually become allies and supporters of the paper.

According to Lewicki et al. (2010: 96-100), integrative bargaining is facilitated when negotiators have faith in their own problem-solving ability, are confident about the validity of their own positions and the viewpoints of the other party, and can engage in communication that is clear and accurate. These principles can help authors navigate the power structure and build coalitions to cooperate with the editors and reviewers in the review process. There is a delicate balance between asserting one's confidence in the paper's contribution and keeping an open mind regarding helpful comments. And framing, detecting, and enlisting support from the editors, reviewers, or external experts can be critical in achieving such a balance.

\section{PROVISO AND PRÉCIS}

At its core, negotiation is an empowering process in which the weak party can participate in a joint decision-making process. A truly integrative negotiation often results in better outcomes for most parties than their alternatives, mutual respect among the parties, and potential development of long-term relationships. By framing the review process as an integrative negotiation, authors can avoid less constructive mindsets that lead to either complete compliance or complete defensiveness. Indeed, Shaw (2012: 1263) suggests that instead of treating the authorreviewer relationship as a 'hostile takeover - arduous and combative', we view this relationship as a 'joint venture', which also takes negotiations to form. Successful integrative negotiations benefit from collaborative efforts, clear and accurate 
communication, and creativity in inventing options for problem solving, each of which is also critical for successful manuscript revision.

I would, however, caution authors not to label responses as 'negotiations with the reviewers' because hearing the term 'negotiation' can actually prime a 'fixed pie' or distributive mindset and reduce integration (e.g., Thompson, 2012). Reviewers and editors may take issue with authors who explicitly describe their approach for addressing a certain comment as bargaining. The purpose of this essay is not to encourage authors to treat the revision dialogue between authors and reviewers as a contentious situation; rather, I propose we consider the process as a collaborative effort to improve the manuscript and draw upon principles and techniques of integrative negotiation to aid in this collaboration. Thus, I am suggesting a change of authors' mindsets rather than proposing a new way to respond to the decision letter. Not every negotiation produces mutually satisfactory outcomes; neither does the revision process. But efforts to create value and to collaborate with others may still result in an improved manuscript, and help authors be more resilient as they move on to the next attempt.

I hope that framing the revision process as an integrative negotiation empowers authors to engage actively and collaboratively with editors and reviewers. Such framing does not replace hard and ethical work on theory building and empirical analysis, analogous to careful preparation and ethical conducts being fundamental winning strategies in negotiation (Chen, 2011; Lewicki et al., 2010; Simons \& Tripp, 1997). Negotiation research teaches us that the combination of an open mind, cooperative spirit, optimism, and gratitude for the value added by others, results not only in tangible benefits for the manuscript itself, but also in profound learning experiences.

\section{TAKING A DEVELOPMENTAL JOURNEY WITH MANAGEMENT AND ORGANIZATION REVIEW}

I am immensely grateful that my first peer-reviewed article was published in Management and Organization Review $(M O R)$. The final version of the paper benefited greatly from multiple rounds of constructive feedback. My survey of other MOR authors, representing both seasoned and junior scholars around the world, overwhelmingly echoes my experience. The authors deeply appreciated the fair, thorough, detailed, rich, and extensive comments from the reviewers, as well as the patient guidance of the editors in developing the papers through several cycles of revision and editing.

One of the most challenging issues that the authors faced in this process was to defend the validity and legitimacy of some indigenous Chinese concepts. Reviewers did not seem to understand the differences between the indigenous ideas and more generally understood terms in the mainstream literature. There were at least a few rounds of rewriting, arguments, and counter arguments between authors and 
reviewers on how to clarify, focus, or balance the Eastern versus the Western approaches. In the end, most authors felt that the final version was an integrated product of collaboration among the authors, reviewers, and editors. Junior authors were especially appreciative of the editorial guidance and the learning experience.

The genuinely constructive culture at $M O R$, and the diverse set of autonomous departmental editors who are open to various theoretical perspectives and empirical methods, provides an optimal situation for authors to negotiate, collaborate, and learn during the review and revision process. The challenging issues also offer opportunities to engage in collaborative efforts with editors and reviewers to further develop the manuscript's contribution. The MOR editorial idea of 'openminded reviewers and assertive authors' (Tsang, 2014) could further facilitate such a developmental journey for authors.

\section{NOTE}

I thank Bruce Barry, Ingrid Fulmer, Kwok Leung, Arie Lewin, Li Ma, Sushil Nifadkar, and Anne Tsui for helpful comments on earlier versions of this paper. Ying Chen, Grace Chun Guo, Peter Ping $\mathrm{Li}$, Lin Lu, Aurelia Mok, and S. Arzu Wasti graciously shared their experience as MOR authors for this article.

\section{REFERENGES}

Ashford, S. J. 1996. The publishing process: The struggle for meaning. In P. J. Frost \& M. S. Taylor (Eds.), Rhythms of academic life: Personal accounts of careers in academia: 119127. Thousand Oaks, CA: Sage.

Chen, X.-P. 2011. Author ethical dilemmas in the research publication process. Management and Organization Review, 7(3): 423-432.

Daft, R. L., \& Lewin, A. Y. 2008. Rigor and relevance in organization studies: Idea migration and academic journal evolution. Organization Science, 19(1): 177-183.

De Dreu, G. K. W., \& Van Kleef, G. A. 2004. The influence of power on the information search, impression formation and demands in negotiation. Journal of Experimental Social Psychology, 40: 303-319.

Fisher, R., Ury, W., \& Patton, B. 2011. Getting to yes: Negotiating agreement without giving in (3rd ed.). New York: Penguin.

Hempel, P. S. 2014. The developmental reviewer. Management and Organization Review, 10(2): 175-181.

Lewicki, R. J., Barry, B., \& Saunders, D. M. 2010. Negotiation (6th ed.). Boston, MA: McGraw Hill.

Murnighan, J. K. 1986. Organizational coalitions: Structural contingencies and the formation processes. In N. R. J. Lewicki, B. H. Sheppard \& M. H. Bazerman (Eds.), Research on negotiation in organizations, vol. 1: 155-173. Greenwich, CT: JAI Press.

Murnighan, J. K. 1996. Revising and resubmitting: Author emotions, editor roles, and the value of dialogue. In P. J. Frost \& M. S. Taylor (Eds.), Rhythms of academic life: Personal accounts of careers in academia: 135-142. Thousand Oaks, CA: Sage.

Putnam, L. L., \& Jones, T. S. 1982. The role of communication in bargaining. Human Communication Research, 8: 262-280.

Rindova, V. 2008. Editor's comments: Publishing theory when you are new to the game. Academy of Management Review, 33(2): 300-303.

Shaw, J. D. 2012. From the Editors: Responding to reviewers. Academy of Management Journal, 55(6): 1261-1263.

Simons, T., \& Tripp, T. 1997. The negotiation checklist: How to win the battle before it begins. Cornell Hospitality Quarterly, 38(1): 14-23. 
Thompson, L. 2012. The mind and heart of the negotiator (5th ed.). Upper Saddle River, NJ: Pearson.

Tsang, E. W. K. 2014. Ensuring manuscript quality and preserving authorial voice: A balancing act of editors. Management and Organization Revieze, 10(2): 191-197.

Tsui, A. S., \& Hollenbeck, J. R. 2009. Successful authors and effective reviewers: Balancing supply and demand in the organizational sciences. Organizational Research Methods, 12(2): 259-275.

Ury, W., Brett, J. M., \& Goldberg, S. B. 1988. Getting disputes resolved: Designing systems to cut the costs of conflict. San Francisco, CA: Jossey-Bass, Inc. 